8a

\title{
Irreversible costs and benefits of transgenic crops: what are they?
}

\author{
Matty Demont ${ }^{\#}$, Justus Wesseler ${ }^{\#}$ and Eric Tollens ${ }^{\#}$
}

\begin{abstract}
The decision of whether to release transgenic crops in the EU is one subject to flexibility, uncertainty and irreversibility. We analyse the case of herbicide-tolerant sugar beet and estimate the maximum irreversible environmental cost that can be tolerated for this technology from a benefit-cost perspective. Among Member States, these costs range from an annual $€ 50$ to $€ 212$ per hectare planted to transgenic sugar beet, i.e. in the range of $27-80 \%$ of the reversible benefits. It is questionable whether the environmental cost of herbicide-tolerant sugar beet would exceed this threshold.
\end{abstract}

Keywords: irreversibility; uncertainty; biotechnology; externality; social benefits and costs; sugar beet

\section{Introduction}

The decision whether or not to release transgenic crops is one subject to uncertainty and irreversibility. This has been recognized by economists (Wesseler 2002; Demont, Wesseler and Tollens 2004; Laxminarayan 2003) as well as biologists (Gilligan 2003). Uncertainty related to the release of transgenic crops exists with regard to the future benefits of the technology as, in general, future output and input prices in agriculture are not known with certainty due to several factors including the microclimate, agriculture policies and technical change.

The irreversible effects of a release of transgenic crops include effects on: human health, due to changes in pesticide use; biodiversity, due to gene drift, impacts on unintended target organisms and on pest resistance; climate change, due to changes in greenhouse-gas emissions; investment in farm equipment due to changed seeding technology; and administrative costs due to new biosafety regulations.

Rejecting the existence of some or all of the effects or rejecting that they are irreversible has brought these irreversibility effects into question. We feel that clarification on the meaning of irreversibility from an economic point of view is important, so as to avoid misunderstanding among economists as well as between economists and biologists. A clarification on this point will not only improve communication, but will also be important for future assessments of the technology.

We proceed by providing a definition of irreversibility and discuss the implications for an economic assessment of biotechnology. We are able to show that the criticism

\footnotetext{
${ }^{\text {\# }}$ Katholieke Universiteit Leuven, de Croylaan 42, B-3001 Leuven, Belgium. E-mail: matty.demont@agr.kuleuven.ac.be; eric.tollens@agr.kuleuven.ac.be

\#\# Environmental Economics and Natural Resources Group, Wageningen University, The Netherlands.

E-mail: justus.wesseler@wur.nl
} 
against the irreversibility effect is due to a misunderstanding concerning the economic interpretation of the irreversibility effect.

\section{What are irreversibilities?}

The effects of irreversibilities on the value of a project, be it an investment by a single investor or a project financed by the government, were analysed in the seminal papers of Arrow and Fisher (1974) and Henry (1974). The basic message is that if one considers an investment with uncertain costs and benefits, irreversible costs and the possibility to postpone the investment (flexibility), then the investment should only be undertaken immediately if the benefits exceed the costs by a certain amount and not if they are equal to or greater than the costs as the standard net-present-value rule suggests. The amount by which the benefits have to exceed the costs under uncertainty, irreversibility and flexibility has been called the quasi-option value. The quasi-option value can be explained by the gains from waiting due to the arrival of new information over time. The concept of the quasi-option value is similar to the real-option value. The real-option value originated from financial economics. In the literature on real-option valuations, the opportunity to invest is valued in analogy to a call option in financial markets. Investors have the right but not the obligation to exercise their investments. This right, the option to invest (real option) has a value, which is a result of the option owner's flexibility. Chavas (1994) provided similar results in his application to investments in agriculture. Dixit and Pindyck (1994) suggest an application of the real-option approach not only to investment problems but to all kinds of decision-making under temporal uncertainty and irreversibility ${ }^{1}$. Recently, the approach has been applied in agriculture to, among others, the adoption of soil-conservation measures (Winter-Nelson and Amegbeto 1998; Shively 2000), marketing (Richards and Green 2000), wilderness preservation (Conrad 2000), agricultural labour migration (Richards and Patterson 1998) and investment in irrigation technology (Carey and Zilberman 2002). Applications related to agricultural biotechnology include studies by Demont, Wesseler and Tollens (2004), Knudsen and Scandizzo (2003), Morel et al. (2003) and Wesseler (2003). Leitzel and Weisman (1999) apply the real-option approach to the analysis of government reforms and argue that new government policies require investments in the form of training of government officials, hiring of additional workers and purchase of equipment. Part of these costs is irreversible and the success of the implemented policy is uncertain, which results under flexibility in a positive value of the option to delay the implementation of the policy.

\section{Decision in the presence of irreversible costs}

We consider the effects of irreversibility, uncertainty and flexibility in the context of releasing and adopting transgenic crops. Consider a sugar-beet farmer who wants to move from non-herbicide-tolerant sugar beets, n-htSB, to herbicide-tolerant sugar beets, htSB. To plant the htSB he needs a new planting machine, as he can increase the spacing of the beets ${ }^{2}$. The average gross margin of the n-htSB is about 1000 Euro per hectare. The gross margin of the htSB is expected to be about 1200 Euro per hectare due to higher yields and lower pesticide use. The expected incremental benefit is therefore 200 Euro per hectare and year received at the end of the year. The example will be kept simple by assuming the incremental benefits are certain and will remain constant forever. The discount rate is $10 \%$. What is the value $V$ of adopting htSB under these assumptions? This is simply the present value of the infinite 
incremental benefit stream, $V=\sum_{t=1}^{t=\infty} 200 \cdot(1.1)^{-t}=\frac{200}{0.1}=2000$. For the decision to invest in htSB the investment costs have to be deducted. Now, let us assume the farmer can sell his old sugar-beet planter for 500 Euro and buys a new one for 2100 Euro. The net investment costs $I$ are 1600 Euro. The net present value, $N P V$, of an investment in htSB is $N P V=V-I=2000-1600=400$. The $N P V$ is positive and we can conclude that a profit-maximizing farmer adopts htSB. This example illustrates a decision under certainty.

Now, we introduce risk about the future incremental benefits. We will assume the incremental benefits can either be high at 300 Euro or low at 100 Euro depending on the price for sugar beets. The farmer will only know at the end of the year whether or not the price for sugar beets and, hence, the incremental benefits will be high or low. Both situations are equally likely and occur with a probability of $q=1-q=0.5$. As by assumption the farmer is risk-neutral, he would invest if the expected present value of the project is positive. The expect value, $E[V]$, of the project is the sum of the probability-weighted two states of nature:

$$
E[V]=0.5 \cdot \sum_{t=1}^{t=\infty} 300 \cdot(1.1)^{-t}+0.5 \cdot \sum_{t=1}^{t=\infty} 100 \cdot(1.1)^{-t}=2000 .
$$

The result is the same as before. Deducting the initial investment costs of 1600 Euro provides the same NPV of 400 as before.

What is the value, $V$, of adopting htSB, if the future incremental benefits are low? This is: $V_{0}=\sum_{t=1}^{t=\infty} 100 \cdot(1.1)^{-t}=1000$. In this case the value of the project does not cover the initial investment costs of 1600 Euro. This would not be a problem if the farmer could easily sell his planting machine after one year for 1600 Euro or a little less due to depreciation from using the machine. In this case the initial investment costs would be reversible.

In most cases it would be difficult to sell the planting machine. The low incremental benefits would not only effect one particular farmer but several and therefore, several farmers would want to sell their machines, whereas there would be almost no one interested in buying. Also, asymmetric information about the quality of the machine and the transaction costs of finding a buyer and negotiating the sale lower the net price of the machine.

In the case he is unable to sell the planting machine, the investment costs are totally irreversible. In the case he has to sell the machine at a price below 1600 Euro, the investment would be partially irreversible or sunk ${ }^{3}$.

Now, we assume the farmer is flexible and can postpone his decision. Would this provide him with any additional gain? Yes, it would, if the investment costs are irreversible. Consider the following: the farmer postpones his investment by one period. In the case the gross margin increases, the $N P V$ of the investment one year from now is: $N P V_{1}=-1600+\sum_{t=2}^{t=\infty} 300 \cdot(1.1)^{-t}=1400 \quad$ or $\quad$ in today's value $N P V_{0}=N P V_{1} / 1.1=1273$. In case the gross margin decreases, the $N P V$ of the investment one year from now is: $N P V_{1}=-1600+\sum_{t=2}^{t=\infty} 100 \cdot(1.1)^{-t}=-600$ or in today's value $N P V_{0}=N P V_{1} / 1.1=-545$. In the latter case the farmer would not invest. The gain from waiting is the gain from avoiding losses of 545 Euro in present value. The economic gain from waiting can be calculated by comparing the expected 
$E\left[N P V_{0}^{I}\right]$ of the immediate investment with the $E\left[N P V_{0}^{P}\right]$ from waiting one year. The $E\left[N P V_{0}^{I}\right]$ from immediate investment is 400 Euro. The $E\left[N P V_{0}^{P}\right]$ is:

$$
E\left[N P V_{0}^{P}\right]=\left[0.5 \cdot\left(-1600+\sum_{t=2}^{t=\infty} 300 \cdot(1.1)^{-t}\right)+0.5 \cdot(0)\right] / 1.1=636 .
$$

The $E\left[N P V_{0}^{P}\right]=636$ and is greater than the $E\left[N P V_{0}^{I}\right]$ of 400 Euro from immediate investment. In this case it would be worthwhile waiting. The economic gain from waiting is the difference between the two, i.e. 236 Euro.

At this point it is worthwhile noting the importance of the irreversibility effect. It only pays to wait when the investment costs are irreversible. This observation will be even more obvious if the incremental net benefit would be negative in the bad case. Then the farmer would immediately stop producing htSB and move back to planting $\mathrm{n}-\mathrm{htSB}{ }^{4}$.

If the initial investment costs were not irreversible, immediate investment would be optimal $^{5}$. Also, it would be optimal to invest immediately if the investment could not be postponed due to other circumstances, such as a contract for planting htSB only offered once.

A third important observation is the opportunity cost of waiting. Waiting pays as the veil of uncertainty will be removed after one year, but at the same time the benefits at the end of year one are foregone. These foregone benefits of expected 200 Euro are the opportunity costs of waiting.

\section{Decision in the presence of irreversible costs and irreversible benefits}

The benefits that have been discussed, the incremental benefits, are reversible. By stopping planting htSB, incremental benefits are also foregone. As there are irreversible costs there are also irreversible benefits. These are benefits that will continue to be present even if the action that has produced them stops. Consider, for example, a one-time subsidy of 500 Euro for planting htSB. There are other examples that will be discussed in more detail later. The $E\left[N P V_{0}^{I}\right]$ increases in this case by exactly 500 Euro and the $E\left[N P V_{0}^{I}\right]=900$. The $E\left[N P V_{0}^{P}\right]$ from waiting in this case is:

$$
E\left[N P V_{0}^{P}\right]=\left[0.5 \cdot\left(-1600+500+\sum_{t=2}^{t=\infty} 300 \cdot(1.1)^{-t}\right)+0.5 \cdot(0)\right] / 1.1=864
$$

The $E\left[N P V_{0}^{I}\right]>E\left[N P V_{0}^{P}\right]$ and there are no gains from waiting. The irreversible benefits reduce the irreversible cost, which leads in this case to an immediate investment.

In the last case, irreversible benefits were considered in the form of a grant. Now, consider the case where the subsidy is in the form of a loan and has to be paid back after ten years. In this case do irreversible benefits matter? Comparing the results of the subsidy as a grant with those as a loan will provide the information. The $E\left[N P V_{0}^{I}\right]$ of an immediate investment in htSB, where the subsidy has to be paid back after ten years, provides the following result:

$$
E\left[N P V_{0}^{I}\right]=-1600+500-\frac{500}{1.1^{10}}+0.5 \cdot\left[\sum_{t=1}^{t=\infty} 300 \cdot(1.1)^{-t}+\sum_{t=1}^{t=\infty} 100 \cdot(1.1)^{-t}\right]=707 .
$$


The $E\left[N P V_{0}^{I}\right]$ of an immediate investment in this case is 707 Euro, which is more than in the case without the subsidy (400 Euro) and less than in the case with the subsidy as a grant (900 Euro).

The result for a postponed investment is the following:

$$
E\left[N P V_{0}^{P}\right]=\left[0.5 \cdot\left(-1600+500-\frac{500}{1.1^{10}}+\sum_{t=2}^{t=\infty} 300 \cdot(1.1)^{-t}\right)+0.5 \cdot(0)\right] / 1.1=776 .
$$

The $E\left[N P V_{0}^{P}\right]$ of an immediate investment in this case is 775 Euro, which is also in this case higher than in the case without the subsidy (636 Euro) and lower than in the case with the subsidy as a grant (864 Euro). We further observe that the optimal decision will be to postpone the investment, wait for one year and to invest if the incremental benefits increase and not to invest if they decrease. Again, we observe positive gains from waiting. The first case, of irreversible benefits, only is similar to the case where the adoption of transgenic crops reduces the use of pesticides that are harmful to human health.

\section{Decision in the presence of irreversible benefits}

Another interesting question related to the irreversible benefits is whether there are gains from waiting if only irreversible benefits and no irreversible costs are present or if the net irreversibility effect is positive. Under a positive net irreversibility effect there will be no gains from waiting, as there are no losses that can be avoided. The $E\left[N P V_{0}^{I}\right]$ in the case of irreversible benefits only is

$$
E\left[N P V_{0}^{I}\right]=500+0.5 \cdot \sum_{t=1}^{t=\infty} 300 \cdot(1.1)^{-t}+0.5 \cdot \sum_{t=1}^{t=\infty} 100 \cdot(1.1)^{-t}=2500
$$

and in the case of the postponed investment:

$$
E\left[N P V_{0}^{P}\right]=0.5\left[500+\sum_{t=2}^{t=\infty} 300 \cdot(1.1)^{-t}+500+\sum_{t=2}^{t=\infty} 100 \cdot(1.1)^{-t}\right] / 1.1=2273 .
$$

The $E\left[N P V_{0}^{I}\right]$ under this scenario will always be greater than the $E\left[N P V_{0}^{P}\right]$ due to the discounting effect and therefore waiting does not provide an economic gain.

The important observations about the irreversible benefits are threefold. First, irreversible benefits reduce irreversible costs and this by the order of one. One unit of irreversible benefits compensates for one unit of irreversible costs. Second, a decrease in irreversible benefits over time, even up to a hundred percent, still has a positive impact on the value of the project. Third, a positive irreversibility effect does not provide economic gains from waiting.

\section{The special case of pest resistance}

An interesting effect to analyse in more detail is the possibility of pest resistance. The susceptibility of pests to control agents has been viewed by economists as a nonrenewable resource, and hence the appearance of pest resistance as an irreversibility. Biologists and entomologists in particular argue that susceptibility to control agents, pesticides in particular, should be viewed as a renewable resource. That is, if pests become resistant to a control agent and consequently the use of the control agent stops, pest resistance breaks down after a while and pests become susceptible again. The important question within the context of this paper is whether or not an irreversibility effect exists. To show that an irreversibility effect indeed exists 
consider the following hypothetical example for $B t$ corn used against damages from the European Corn Borer (ECB). The incremental benefits from adopting $B t$ corn are assumed to be 200 at the beginning, period one, and due to price uncertainty increase to either 300 or 100 after one time period and remain at the level until the end of the fourth period. At the end of the fourth period the ECB becomes resistant to $B t$ corn and the incremental benefits decrease to zero from period five till the end of period seven. At the end of period seven, the ECB becomes susceptible again to $B t$ corn. To keep the example simple, we assume that the incremental benefits increase to 200 Euro until infinity as the ECB will also be susceptible till infinity. The example is illustrated in Figure 1. The costs of pest resistance in present value terms are 1600 Euro. These are extra costs beyond the lost incremental benefits of periods five, six and seven.

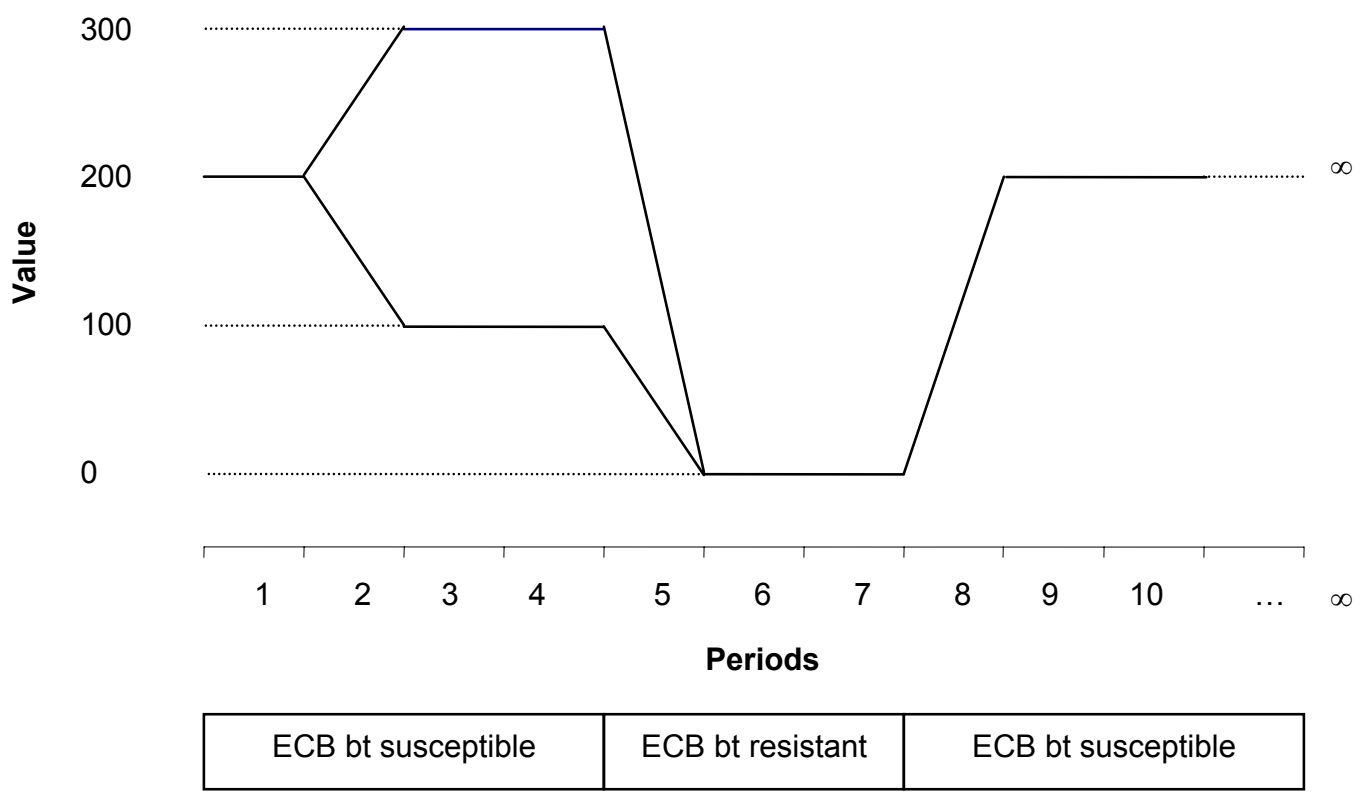

Figure 1. Example for appearance and breakdown of ECB resistance to $B t$ toxin

The value of $B t$ corn from immediate adoption is:

(8) $E\left[N P V_{0}^{I}\right]=-1600+200 \cdot 1.1^{-1}+0.5 \cdot \sum_{t=1}^{t=4} 300 \cdot(1.1)^{-t}+0.5 \cdot \sum_{t=1}^{t=4} 100 \cdot(1.1)^{-t}+\sum_{t=8}^{t=\infty} 200 \cdot(1.10)^{-t}=60$.

The result for a postponed adoption is:

$$
E\left[N P V_{0}^{P}\right]=\left[0.5 \cdot\left(-1600+\sum_{t=2}^{t=5} 300 \cdot(1.1)^{-t}+\sum_{t=9}^{t=\infty} 200 \cdot(1.1)^{-t}\right)\right]=171 .
$$

The above example illustrates that even though pest resistance can be reversible from a biological point of view, from an economic point of view an irreversibility effect may exist.

All the examples that have been discussed were constructed in a way that it was always optimal from an economic point of view to delay the adoption of transgenic crops. What is important to note is that while an irreversibility effect exists, it will not always be optimal to postpone the adoption. In cases where the irreversible costs are small or the incremental benefits are high, immediate adoption can be optimal. 


\section{Private and public irreversibilities}

In the example we did not differentiate between irreversible benefits and costs. For the assessment of benefits and costs of transgenic crops and for the decision whether or not to release them, a distinction between private and social benefits and costs of transgenic crops has to be made. Private costs and benefits are important for the analysis of the adoption potential among farmers. This will provide information about the expected aggregated private net benefits from introduction. In addition, external benefits and costs have to be considered. These include, among others, climatechange effects, impacts on biodiversity and impacts on farmers' health. Further, the examples of the previous chapter illustrate the necessity of a differentiation between reversible and irreversible costs and benefits. A two-dimensional matrix (or threedimensional one, if benefits and costs are added as an additional dimension) can be designed considering these differentiations for an ex ante analysis of social costs and benefits of transgenic crops as depicted in Figure 2. A complete ex ante analysis of economic benefits and costs of transgenic crops should consider all four quadrants of Figure 2.

\begin{tabular}{|c|c|c|}
\hline $\begin{array}{l}\text { Scope } \\
\text { Reversibility }\end{array}$ & Private & External \\
\hline Reversible & $\begin{array}{l}\text { Quadrant } 1 \\
\text { Private Reversible Benefits }(P R B) \\
\text { Private Reversible Costs }(P R C)\end{array}$ & $\begin{array}{l}\text { Quadrant } 2 \\
\text { External Reversible Benefits }(E R B) \\
\text { External Reversible Costs }(E R C)\end{array}$ \\
\hline Irreversible & $\begin{array}{l}\text { Quadrant } 3 \\
\text { Private Irreversible Benefits }(P I B) \\
\text { Private Irreversible Costs }(P I C)\end{array}$ & $\begin{array}{l}\text { Quadrant } 4 \\
\text { External Irreversible Benefits }(E I B) \\
\text { External Irreversible Costs }(E I C)\end{array}$ \\
\hline
\end{tabular}

Figure 2. The two dimensions of an ex ante analysis of social benefits and costs of transgenic crops

As an example we use an ex ante assessment of herbicide-tolerant sugar beets (htSB) in Europe as explained in detail in Demont, Wesseler and Tollens (2004). The decision rule to release htSB is formulated as, to release htSB if the net reversible social benefits $W$, the sum of quadrant 1 and quadrant 2 in Figure 2, are greater than the net irreversible costs, the sum of quadrant 3 and quadrant 4 , multiplied by a factor greater than one, the so-called hurdle rate $\eta$ :

(10) $W \geq(I-R) \cdot \eta$.

As the social irreversible costs, $I=P I C+E I C$, and benefits, $R=P I B+E I B$, of transgenic crops are highly uncertain, instead of identifying the net reversible social benefits $W$ required to release transgenic crops in the environment, the maximum tolerable social irreversible costs $I^{*}$ under given net social reversible benefits $W$ and social irreversible benefits $R$ are identified:

(11) $I^{*}=R+W / \eta$.

The results are presented in Table 1 . The estimated hurdle rates are entirely coherent with the expectations. We observe a bimodal distribution. Low-cost sugar- 
beet producers such as France, Belgium, the Netherlands, Germany, Denmark, the UK and Italy have low hurdle rates (1.25-1.82), while high-cost areas like Spain, Ireland, Austria, Sweden, Greece and Finland have higher ones (2.10-3.69), requiring higher values of $W$ to justify a release of HT sugar beet.

The values of $W, R$, and $I^{*}$ are presented as annuities of an infinite and continuous stream of benefits and costs, respectively, per hectare planted to transgenic sugar beet. $W$ ranges from 121 Euro to 354 Euro with an average of 199 Euro per hectare. Highcost areas generally have high values for $W$, which can be explained by the EU sugar policy. Except a few outliers, estimates for $R$ are low and range from 0.18 Euro to 3.36 Euro with an average of 1.59 Euro per hectare. This is due to the fact that we use conservative estimates from literature for the average external social cost of pesticide application. The maximum tolerable social irreversible costs range from 50 Euro to 212 Euro per hectare, i.e. in the range of $27-80 \%$ of the annual net private reversible benefits. For the EU as a whole this means that it should accept transgenic sugar beets as long as social irreversible costs do not exceed 121 Euro per hectare, totalling 103 million Euro per year. There is a large divergence between estimates for $R$ and $I^{*}$. For the EU, e.g., $I^{*}$ is 76 times larger than $R$. The social irreversible benefits $R$ include impact of pesticide use on the environment, biodiversity and climate. As the social irreversible costs $I^{*}$ include the same environmental effects, it is hard to believe that they are higher by a factor of 76 . The total net private reversible benefits forgone, $W$, if the de facto moratorium is not lifted are in the order of 169 million Euro per year.

On the other hand, the social reversible net benefits plus the social irreversible benefits are only about one Euro per household in the EU. If households put a value on the potential irreversible costs of transgenic crops of one Euro or more, than the $e x$ ante net social benefits of htSB are negative and htSB should not be released.

Table 1. Hurdle rates and annual net private reversible benefits $(W)$, social irreversible benefits $(R)$, and maximum tolerable social irreversible costs $\left(I^{*}\right)$ per hectare transgenic sugar beet

\begin{tabular}{|c|c|c|c|c|c|}
\hline Member State & $W(€ / \mathbf{h a})$ & $R$ (€/ha) & Hurdle rate & $I *(€ /$ ha $)$ & Total $I^{*}(€)$ \\
\hline Austria & 251 & 3.36 & 2.88 & 91 & $1,842,164$ \\
\hline Belgium \& & 168 & 2.09 & 1.26 & 135 & $5,852,023$ \\
\hline Luxembourg & & & & & \\
\hline Denmark & 178 & 2.06 & 1.73 & 105 & $2,864,870$ \\
\hline Finland & 251 & 0.74 & 3.69 & 69 & 976,108 \\
\hline France & 179 & 1.05 & 1.25 & 145 & $24,964,742$ \\
\hline Germany & 179 & 1.57 & 1.36 & 134 & $27,846,376$ \\
\hline Greece & 264 & $7.97^{\mathrm{b}}$ & 3.12 & 93 & $1,771,502$ \\
\hline Ireland & 116 & $-0.96^{\mathrm{b}}$ & 2.29 & 50 & 691,951 \\
\hline Italy & 330 & 2.32 & 1.82 & 183 & $22,682,730$ \\
\hline The Netherlands & 121 & 0.83 & 1.31 & 94 & $4,630,433$ \\
\hline Portugal & 354 & $-0.65^{b}$ & $1.67^{\mathrm{c}}$ & 212 & 615,218 \\
\hline Spain & 252 & 0.53 & 2.10 & 121 & $7,258,219$ \\
\hline Sweden & 150 & 0.18 & 3.01 & 50 & $1,226,127$ \\
\hline UK & 127 & 1.78 & 1.76 & 74 & $5,135,522$ \\
\hline $\mathbf{E U}$ & 199 & 1.59 & $1.67^{\mathrm{a}}$ & 121 & $102,628,681$ \\
\hline
\end{tabular}

\footnotetext{
${ }^{\mathrm{a}}$ Sugar beet area-weighted average of the individual Member States' hurdle rates.

${ }^{\mathrm{b}}$ The extreme estimates for Greece, Ireland and Portugal are probably due to data inconsistencies. These countries only cover $4 \%$ of total EU sugar-beet area, almost not affecting the EU average.

${ }^{\mathrm{c}}$ No data on margins have been found for Portugal. We use the EU area-weighted average. Source: Demont, Wesseler and Tollens (2004).
} 


\section{Conclusion}

In this paper we have shown the multi-dimensional features of the irreversibility effect for the ex ante assessment of social benefits and costs of transgenic crops. We have demonstrated the irreversibility effect by using very simple examples. They illustrate the differences between irreversible benefits and irreversible costs. In addition, the example of pest resistance shows the difference between irreversibility at the biological and economic level. While pest resistance can be considered reversible from a biological point of view, it may nevertheless result in irreversible costs. The different types of irreversibilities are summarized in a two-dimensional matrix that we propose as a guideline for a complete ex ante analysis of social benefits and costs of transgenic crops. An application for the decision to release herbicide-tolerant sugar beets in the EU illustrates the use of the matrix.

\section{References}

Amram, M. and Kulatilaka, N., 1999. Real options: managing strategic investment in an uncertain world. Harvard Business School Press, Boston.

Arrow, K.J. and Fisher, A.C., 1974. Environmental preservation, uncertainty, and irreversibility. Quarterly Journal of Economics, 88 (2), 312-319.

Carey, J.M. and Zilberman, D., 2002. A model of investment under uncertainty: modern irrigation technology and emerging markets in water. American Journal of Agricultural Economics, 84 (1), 171-183.

Chavas, J.P., 1994. Production and investment decisions under sunk cost and temporal uncertainty. American Journal of Agricultural Economics, 76 (1), 114-127.

Conrad, J.M., 2000. Wilderness: options to preserve, extract, or develop. Resource and Energy Economics, 22 (3), 205-219.

Demont, M., Wesseler, J. and Tollens, E., 2004. Biodiversity versus transgenic sugar beet: the one Euro question. European Review Agricultural Economics, 31 (1), $1-18$.

Dixit, A., 1989. Entry and exit decisions under uncertainty. The Journal of Political Economy, 97 (3), 620-638.

Dixit, A.K. and Pindyck, R.S., 1994. Investment under uncertainty. Princeton University Press, Princeton.

Gilligan, C.A., 2003. Economics of transgenic crops and pest resistance: an epidemiological perspective. In: Laxminarayan, R. ed. Battling resistance to antibiotics and pesticides: an economic approach. Resources for the Future, Washington, 238-259.

Henry, C., 1974. Investment decisions under uncertainty: the "irreversibility effect". American Economic Review, 64 (6), 1006-1012.

Knudsen, O. and Scandizzo, P.L., 2003. Environmental liability and research and development in biotechnology: a real options approach. In: Evenson, R.E. and Santaniello, V. eds. The regulation of agricultural biotechnology. CABI, Wallingford.

Laxminarayan, R., 2003. Battling resistance to antibiotics and pesticides: an economic approach. Resources for the Future, Washington.

Leitzel, J. and Weisman, E., 1999. Investing in policy reform. Journal of Institutional and Theoretical Economics, 155 (4), 696-709.

Merton, R.C., 1998. Applications of option-pricing theory: twenty-five years later. American Economic Review, 88 (3), 323-349. 
Morel, B., Farrow, S., Wu, F., et al., 2003. Pesticide resistance, the Precautionary Principle and the regulation of Bt corn: real and rational option approaches to decision making. In: Laxminarayan, R. ed. Battling resistance to antibiotics and pesticides: an economic approach. Resources for the Future, Washington, 184-213.

Pindyck, R.S. and Rubinfeld, D.L., 1995. Microeconomics. 3rd edn. Prentic-Hall International, Englewood Cliffs.

Richards, T.J. and Green, G., 2000. Economic hysteresis in variety selection: why grow no wine before its time? In: Peters, G.H. and Pingali, P. eds. Tomorrow's agriculture: incentives, institutions, infrastructure and innovations: proceedings of the twenty-fourth International Conference of Agricultural Economists, Berlin, 13-18 August 2000. Ashgate, Aldershot.

Richards, T.J. and Patterson, P.M., 1998. Hysteresis and the shortage of agricultural labor. American Journal of Agricultural Economics, 80 (4), 683-695.

Shively, G., 2000. Investing in soil conservation when returns are uncertain: a real options approach. In: Peters, G.H. and Pingali, P. eds. Tomorrow's agriculture: incentives, institutions, infrastructure and innovations: proceedings of the twenty-fourth International Conference of Agricultural Economists, Berlin, 13-18 August 2000. Ashgate, Aldershot.

Special issue on irreversibility, 2000. Resource and Energy Economics, 22 (3).

Wesseler, J., 2002. The economics of agrobiotechnology. In: Knowledge support for sustainable development. EOLSS Publishers, Oxford. Encyclopedia of life support systems vol. 1, chapter 3.4.6.58.4.11.

Wesseler, J., 2003. Resistance economics of transgenic crops under uncertainty. In: Laxminarayan, R. ed. Battling resistance to antibiotics and pesticides: an economic approach. Resources for the Future, Washington, 214-237.

Winter-Nelson, A. and Amegbeto, K., 1998. Option values to conservation and agricultural price policy: application to terrace construction in Kenya. American Journal of Agricultural Economics, 80 (2), 409-418.

\footnotetext{
${ }^{1}$ Nobel laureate Robert C. Merton (1998) provides an overview of the application of the option-pricing theory outside financial economics. The book by Amram and Kulatilaka (1999) includes several case studies of real-option pricing. The special issue on irreversibilities of the journal Resource and Energy Economics, volume 22 (2000) includes application in the field of environmental and natural-resource economics.

${ }^{2}$ Note, this is a simplifying assumption and not necessarily correct for the case of sugar beets. The assumption has been made for convenience, as the empirical application in section 4 will be on htSB.

${ }^{3}$ The investment costs are sunk costs, as they are costs that cannot be recovered and do not affect future economic decisions ignoring the irreversibility effect (Pindyck and Rubinfeld 1995, p. 197). This changes if irreversibilities are considered (Dixit 1989).

${ }^{4}$ Assuming he does not need to buy a new planter and can still use the old one he used before switching to htSB.

${ }^{5}$ This would be the case if the planter could be used for n-htSB and htSB as well.
} 